\title{
Overview of the use of recombinant factor VIla in children
}

This article was published in the following Dove Press journal:

Pediatric Health, Medicine and Therapeutics

13 October 2014

Number of times this article has been viewed

\section{John Puetz}

Department of Pediatrics, Division of Hematology/Oncology, Cardinal Glennon Children's Medical Center, Saint Louis University, St Louis, MO, USA
Correspondence: John Puetz Department of Pediatrics, Division of Hematology/Oncology, Cardinal Glennon Children's Medical Center, Saint Louis University, I465 S Grand Boulevard, St Louis, MO 63104, USA $\mathrm{Tel}+$ I 3 |4 5775332

Fax + I 3145775309

Email puetzjj@slu.edu
Abstract: Recombinant factor VIIa (rFVIIa) was initially developed as a bypassing agent to control bleeding in people with hemophilia who have inhibitors. Due to its potential as a universal hemostatic agent, rFVIIa has also been used for a variety of other clinical indications. Investigations into the use of rFVIIa in children have demonstrated clinical efficacy and excellent safety when used for children with hemophilia and inhibitors. Investigations into the use of rFVIIa in children for alternative indications have been hampered by the lack of high-quality evidence. Most studies have shown that rFVIIa can be effective in reducing bleeding and blood product usage when given off-label in children. However, thrombotic events have been reported. In addition, no mortality benefit has been shown for rFVIIa. Despite this, over the last decade, the use of rFVIIa for indications beyond hemophilia has increased dramatically.

Keywords: rFVIIa, children, hemophilia, off-label, inhibitor, neonate

\section{The need for bypassing agents}

One of the more remarkable achievements of 20th century medicine was the determination of the cause of and development of therapies for hemophilia. Descriptions of what would later be called hemophilia can be found in ancient texts such as the Babylonian Talmud. ${ }^{1}$ For thousands of years, nothing could be done to stop the bleeding associated with hemophilia. In the first half of the 20th century, hemophilia was found to be caused by a deficiency of an antihemophilic factor found in the plasma fraction of blood. ${ }^{2}$ The infusion of whole blood or plasma allowed surgical procedures to be successfully performed in people with hemophilia. ${ }^{3}$ In the second half of the century, the development of cryoprecipitate, and later, coagulation factor concentrates, revolutionized care. ${ }^{4}$ People with hemophilia could start to treat their own bleeding episodes, oftentimes in the home. Unfortunately, coagulation factor concentrates produced in the 1970s and early 1980s were not subjected to viral inactivation techniques, which led to the transmission of hepatitis B and C, and HIV. It would take until the last third of the century to produce coagulation factor concentrates that were free of the transmission of hepatitis viruses and HIV, the isolation of the factor VIII and IX genes, and the production of recombinant factor VIII and factor IX replacement therapies. ${ }^{5}$ Another great advancement was the realization that many of the bleeding complications of hemophilia could be greatly reduced by infusing factor VIII or factor IX on a prophylactic schedule. ${ }^{6,7}$ By the end of the 20th century, many of the complications of hemophilia, including joint arthropathy and transmission of infectious agents, had been curtailed. The one major hurdle that remains into the 21 st century is the development of an immune response to factor replacement therapy. 
Because people with hemophilia are born with absent or abnormally structured factor VIII or factor IX, exposure to normally structured factor replacement can cause the development of an immune response to infused factor known as an inhibitor. Inhibitory antibodies quickly render infused factor replacements nonfunctional. This means that factor VIII or factor IX replacement can no longer be used to control bleeding and agents that bypass the need for factor VIII or factor IX must be used.

\section{The coagulation system}

Early investigations of the coagulation system led to the proposal of the coagulation cascade or waterfall hypothesis (Figure 1) ${ }^{8,9}$ In this scheme, each coagulation factor activates a downstream coagulation factor with amplification at each step, ultimately leading to the conversion of soluble fibrinogen into insoluble fibrin and the formation of a fibrin clot. There were two proposed pathways leading to the formation of fibrin, known as the intrinsic and extrinsic pathways. There was also overlap between the two pathways, known as the common pathway. While these pathways were successful at explaining in vitro coagulation, especially coagulation in glass test tubes, some observations raised concerns about the validity of the coagulation cascade. One concern was the observation that people with factor XII deficiency do not suffer from abnormal bleeding. Despite laboratory tests (activated prothrombin time [aPTT]) that are very abnormal, and abnormal clotting in vitro (especially in glass tubes), people with factor XII deficiency do not have recurrent abnormal bleeding. Also, the discovery of the extrinsic pathway left the

\section{Intrinsic cascade}
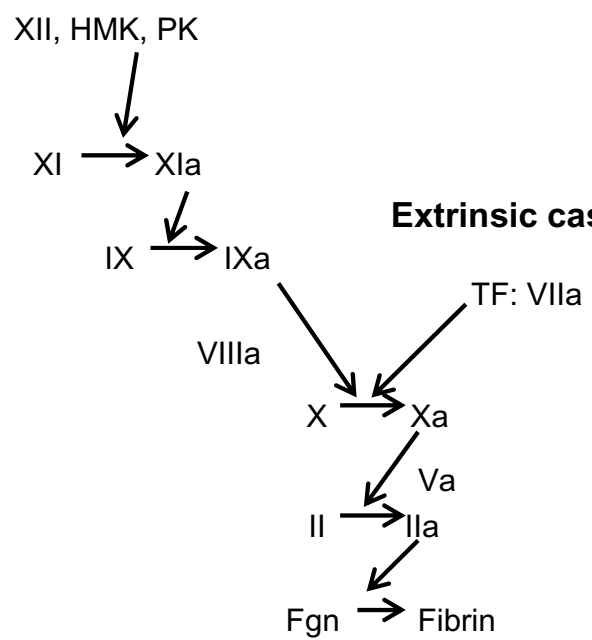

Figure I The classic waterfall or cascade model of hemostasis.

Abbreviations: a, activated factor; Fgn, fibrinogen; HMK, high molecular weight kininogen; Ila, thrombin; PK, prekallikrein; TF, tissue factor; $\mathrm{Xa}$, activated factor $\mathrm{X}$. reason why people with hemophilia have abnormal bleeding unanswered. If fibrin could be generated through the extrinsic cascade, which does not need factor VIII or factor IX, why should people with factor VIII or factor IX deficiency have abnormal bleeding?

Discoveries over the last few decades have found answers to each of these questions and led to another proposed explanation of the hemostatic system (Figure 2).$^{10}$ Investigators now believe that hemostasis is triggered by the exposure of tissue factor (TF)-bearing cells to blood. Under normal physiologic conditions, blood remains within blood vessels and is not exposed to TF. However, when the vessel is damaged, blood is exposed to extravascular tissues and TF. The coagulation factor that initiates the hemostatic system is factor VII. ${ }^{10,11}$ The majority of factor VII circulates in an inactive state and when factor VII binds to TF, no further reaction takes place. However, a small percentage of the circulating factor VII is activated. The binding of activated factor VII (FVIIa) to TF causes the formation of a complex that can activate factor $\mathrm{X}$. The activated factor X (Xa) can then activate factor II (also known as prothrombin) to IIa (thrombin), and as in the waterfall hypothesis, thrombin can generate fibrin from fibrinogen. Thrombin can also activate platelets. Although this pathway, known variously as the tissue factor pathway, or initiation phase, can generate fibrin, it cannot generate enough fibrin to form a stable fibrin clot.

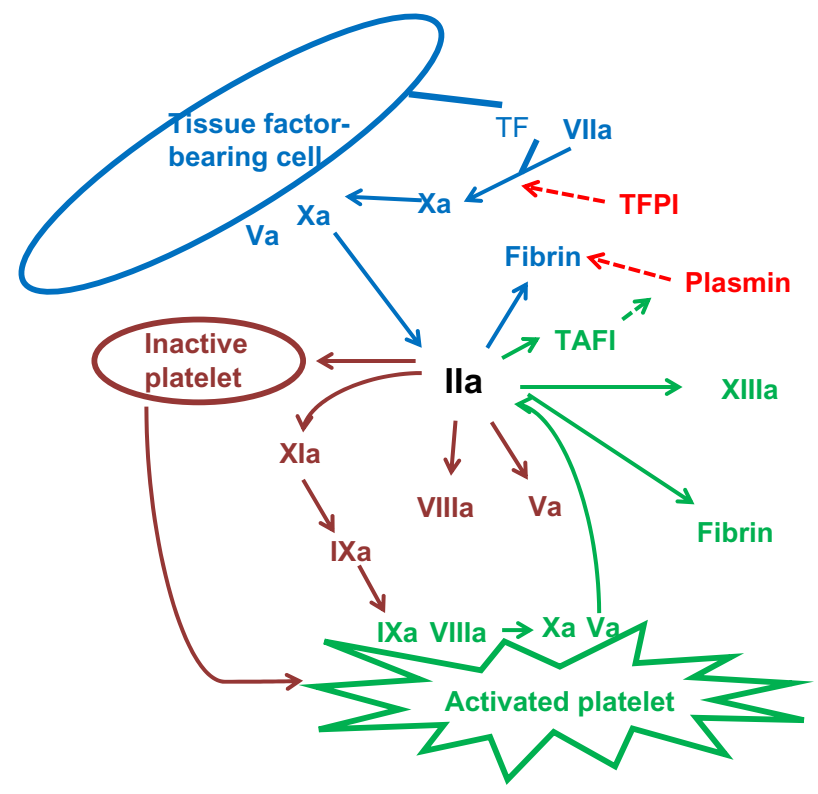

Figure 2 The cell-based model of hemostasis.

Notes: Initiation phase in blue, amplification phase in brown, and propagation phase in green. Solid arrows indicate facilitation of a reaction, and dotted arrows indicate inhibition.

Abbreviations: a, activated factor; lla, thrombin; TAFI, thrombin-activatable fibrinolysis inhibitor; TF, tissue factor; TFPI, tissue factor pathway inhibitor; $\mathrm{Xa}$, activated factor $\mathrm{X}$. 
This is because the TF:FVIIa complex is rapidly inhibited by a protein known as the tissue factor pathway inhibitor (TFPI), and the small amount of formed fibrin can be rapidly degraded by plasmin. ${ }^{10,11}$ In order to form a stable clot, additional fibrin must be generated. This is accomplished from the thrombin that was initially generated from the initiation phase. The next phase of clot formation is known as the amplification phase. Thrombin can activate factor XI, which can activate factor IX (IXa). On the surface of activated platelets, IXa forms a complex with factor VIII, known as the Xase complex. The Xase complex can activate factor $\mathrm{X}$, which along with its cofactor, factor $\mathrm{V}$, forms the prothrombinase complex, which activates more thrombin, which can then activate more factor XI, creating a feedback loop and amplification in the generation of thrombin. The burst of thrombin, known as the propagation phase, is responsible for the formation of a sufficient amount of fibrin to form a stable clot. The thrombin burst also activates factor XIII, which crosslinks fibrin, giving the clot more stability. It can also inhibit fibrinolysis by activating thrombin-activatable fibrinolysis inhibitor (TAFI). Thus, people with hemophilia do not bleed because they cannot generate fibrin - they have abnormal bleeding because they cannot generate the burst of thrombin which is necessary for the formation of a stable, cross-linked, fibrin clot. If a patient with hemophilia develops an inhibitor, rendering factor replacement useless, alternative means of generating thrombin must be sought in order to control bleeding.

The achievement of hemostasis in people with inhibitors takes advantage of the initiation phase and its ability to generate thrombin. One of two types of bypassing agents is generally used to control bleeding in people with hemophilia with inhibitors. ${ }^{11}$ One type, known as an activated prothrombin complex concentrate (aPCC) is produced from pooled, donated, virally inactivated plasma, and contains activated factors II, VII, IX, and X. The other bypassing agent is recombinant factor VIIa (rFVIIa). As one might expect, the infusion of rFVIIa increases the proportion of FVIIa that can bind with TF, and increases the likelihood of forming a TF:FVIIa complex that initiates the coagulation cascade. In addition, it has now been shown that supraphysiologic concentrations of rFVIIa can activate factor $\mathrm{X}$ on the surface of activated platelets in a TF-independent mechanism. ${ }^{10}$ Through these mechanisms, rFVIIa can lead to the generation of a thrombin burst and formation of a stable fibrin clot.

It should be noted that while the hemostatic pathways presented above represent our current understanding, several questions remain to be resolved, including the role of red cells in hemostasis. ${ }^{12}$ An up-to-date description of the hemostatic pathways can be found on the Reactome website. ${ }^{13}$

\section{rFVIla use in hemophilia}

Evidence began to mount that the principal factor responsible for hemostasis in aPCCs was FVIIa. ${ }^{14}$ Because of this, Hedner and Kisiel developed a plasma-derived FVIIa concentrate for use in hemophilia patients with inhibitors. ${ }^{15}$ Based on success with use of plasma-derived FVIIa, a recombinant activated product was developed. rFVIIa was initially investigated in preclinical studies involving animals. Then, pharmacokinetic studies were done in humans. Based on these results, in 1988, Hedner gave a hemophilia patient with an inhibitor rFVIIa to control bleeding during a synovectomy procedure. ${ }^{16}$ Following this success, rFVIIa was made available for compassionate use. Over the next 10 years, over 400 patients, mostly children, received rFVIIa to control bleeding. ${ }^{17}$

Nearly simultaneous to the compassionate use program, controlled clinical studies were performed. ${ }^{18-20}$ The initial study was a blinded study of one of two doses of rFVIIa in children with hemophilia who may or may not have had an inhibitor. This study demonstrated no difference in response to the two doses, and $70 \%$ of patients had good or excellent control of bleeding. ${ }^{18}$ Because of the delay in receiving rFVIIa in the first study, a home study was conducted so that subjects could receive study medication in a timely manner. ${ }^{19}$ This study was an open-label study of hemophilia patients with inhibitors. Subjects received a $90 \mu \mathrm{g} / \mathrm{kg}$ dose of rFVIIa within 8 hours of the onset of a bleeding episode. Finally, a surgical study was performed. Patients with hemophilia and inhibitors undergoing a surgical procedure were randomized to either $35 \mu \mathrm{g} / \mathrm{kg}$ or $90 \mu \mathrm{g} / \mathrm{kg}$ rFVIIa prior to the procedure and every 2 hours for 48 hours. Although there was no difference in the initial hemostatic efficacy between the two groups, fewer subjects receiving the lower dose were able to maintain hemostasis the following 3 days. ${ }^{20}$ Based on the results of these studies, and the experience gained during compassionate use, rFVIIa was approved for use to treat hemophilia patients with inhibitors. Ninety micrograms per kilogram of body weight given intravenously every 2 hours was the approved dose. Since its approval, rFVIIa has been infused for over 1.5 million doses in people with hemophilia and has an excellent safety record when used to treat hemophilia patients with inhibitors. ${ }^{21}$ No transmission of an infectious agent has been documented. Thrombotic events are rare, with a prevalence of four per 100,000 doses. ${ }^{21}$

Because of the short half-life of rFVIIa and the need to infuse every 2 hours, alternative dosing regimens have 
been explored. ${ }^{11}$ Investigations have suggested that the thrombin burst could be optimized at an rFVIIa concentration of $150 \mathrm{nM} .^{22}$ This is achieved by dosing rFVIIa at $300 \mu \mathrm{g} / \mathrm{kg}$ every 6 hours rather than $90 \mu \mathrm{g} / \mathrm{kg}$ every 2 hours. Comparative studies of these two doses have demonstrated equal hemostatic efficacy without additional safety issues, and easier convenience with the high-dose rFVIIa. ${ }^{11}$ Continuous infusion of rFVIIa for surgical procedures and prophylactic dosing of rFVIIa to prevent bleeding in hemophilia patients with inhibitors have also been investigated. ${ }^{23,24}$ Although successes with both continuous infusion and prophylaxis have been reported, continuous infusion may not necessarily reduce the amount of rFVIIa used..$^{25}$ The use of rFVIIa prophylactically may cost over one million US dollars per year. ${ }^{26,27}$

rFVIIa is also approved in many countries to treat factor VII deficiency. Because the plasma concentration of FVII is less in these subjects than inhibitor patients, lower doses of rFVIIa replacement are recommended to treat FVII-deficient patients. ${ }^{28}$ rFVIIa is also approved in several countries to treat congenital platelet disorders such as Glanzmann's thrombasthenia. ${ }^{29}$

Because of its mechanism of action, and its success in treating patients with congenital bleeding disorders besides hemophilia, rFVIIa has been investigated as a "universal hemostatic agent" in a variety of situations in patients with abnormal bleeding.

\section{Off-label use of rFVIla}

One of the initial descriptions of the use of rFVIIa in a bleeding patient who did not have a congenital bleeding disorder was by Kenet et al who illustrated the use of rFVIIa in a trauma patient. ${ }^{30}$ This case report demonstrated the successful achievement of hemostasis in a massively transfused patient who had failed standard therapy. Following this, rFVIIa use was described for a variety of clinical indications, including liver disease, neonatal bleeding, surgical bleeding, trauma, intracranial hemorrhage, hematopoietic stem cell transplant, and obstetric bleeding. ${ }^{11,31-33}$ The majority of initial publications generally represented case reports or small retrospective case series. A review of the early case reports and series describing off-label rFVIIa use in children was completed by Mathew. ${ }^{34}$ Nearly all of the initial case reports showed a beneficial effect of rFVIIa. More than 60 case reports describing the use of rFVIIa in children have been published to date. ${ }^{35}$ Since case reports showing a beneficial effect of a new therapy are more likely to be published than studies that do not show a benefit, the initial successes of rFVIIa in achieving hemostasis in children with a variety of conditions may be attributed to publication bias, and a higher level of evidence should be sought.

The highest level of evidence is prospective randomized controlled trials (RCTs), and especially meta-analysis of prospective RCTs. While at least 29 randomized trials have involved rFVIIa, only three have involved children. ${ }^{36}$ All three had small sample sizes and other methodological concerns. ${ }^{37-39}$ One study measured the change in the prothrombin time (PT) following the administration of rFVIIa or fresh frozen plasma (FFP) in neonates. ${ }^{37}$ Only eleven neonates were included in this randomized trial. While the efficacy of rFVIIa was demonstrated in this study, the clinical utility of the PT in neonates has come into question, making the usefulness of rFVIIa in lowering the PT in neonates who are not bleeding of dubious applicability. ${ }^{31} \mathrm{~A}$ second trial was a double-blind RCT in children with Dengue hemorrhagic fever. ${ }^{38}$ Although bleeding control was successful or partially successful in 15 of 16 children who received rFVIIa compared to four of nine placebo patients, this did not translate into a reduced level of blood product usage. One randomized study described rFVIIa use in children undergoing cardiothoracic surgery (CTS). In the study by Ekert et al, 42 children were randomized in a double-blind fashion to receive rFVIIa prophylactically prior to CTS and compared to 42 children who received standard hemostatic therapy. ${ }^{39}$ Children receiving rFVIIa had a longer time to chest closure than the standard treatment group; otherwise, no differences were shown between the two groups. Thrombotic events were not reported in any children involved in prospective RCTs of rFVIIa.

There have also been a limited number of retrospective comparative studies with reasonable sample sizes. ${ }^{40-43}$ Puetz et al compared neonates receiving rFVIIa to those receiving FFP. This study demonstrated good control of bleeding in the neonates receiving rFVIIa, and no difference in the rate of thrombotic events between the two groups. ${ }^{40}$ Three studies compared children undergoing CTS who received rFVIIa for excessive bleeding compared to a control group. ${ }^{41-43}$ These studies all showed a reduction in transfusion requirements or chest tube drainage in the children receiving rFVIIa. Thrombotic events were reported in two of these studies. In the Karsies et al study, there was no statistical difference in the rate of thrombotic events between cases and controls. ${ }^{43}$ In the Agarwal et al study, six of the 24 children receiving rFVIIa had thrombotic events, including one in the extracorporeal membrane oxygenation circuit, one related to an arterial line, and four mediastinal clots. ${ }^{42}$ The rate of thrombotic events in the control group was not reported. 
Several large retrospective single institution, multiinstitution, registries, and database studies have reviewed rFVIIa use in non-hemophilia patients (Table 1 ) ${ }^{44-50} \mathrm{~A}$ review of the Pediatric Health Information System (PHIS) database involving over 30 US Children's Hospitals and 3,655 admissions by Witmer et al demonstrated that rFVIIa use for off-label indications rose dramatically between 2000-2007 and was associated with a significant number of thrombotic events. ${ }^{47}$ This study did not assess the effectiveness of rFVIIa. Other large case series have evaluated the effectiveness of rFVIIa, and in general, did show a reduction in blood product usage following rFVIIa (Table 1). ${ }^{44-46,48-50}$ Thrombotic events were also reported in these series, but since there was no comparison to a control group, it is difficult to know if the rate of thrombotic events is greater than what would be expected in similar groups of critically ill children who did not receive rFVIIa. There was also a high mortality rate associated with rFVIIa, although in many studies it could not be determined to what degree rFVIIa might have contributed to the high mortality rate. rFVIIa is often times given to the most critically ill children in a desperate, or perhaps futile attempt to stop bleeding.

Since one of the most common indications identified in the large case series was children undergoing CTS, additional attention will be paid to these studies. Approximately 40 studies have described the use of rFVIIa in children undergoing CTS and have been reviewed by Okonta et al and Guzzetta et al. ${ }^{51,52}$ Many of the studies involved case reports or small series. In general, studies of CTS have showed a reduction in bleeding and blood product usage following CTS. Thrombotic events were reported, but again, since comparative studies were typically not done, the rate of thrombotic events is difficult to interpret.

The dose of rFVIIa used in off-label pediatric studies varied greatly, but generally was around $90 \mu \mathrm{g} / \mathrm{kg}$. It is unclear if the dose of rFVIIa used to treat children with hemophilia is the appropriate dose to use in other clinical situations.

A mortality benefit to the use of rFVIIa in children has never been shown. Likewise, a mortality benefit in adults has also never been shown. ${ }^{36,53}$ In addition, other clinical benefits in randomized studies involving adults have not been consistently demonstrated. ${ }^{36,53}$ An increased risk of arterial thrombotic events has been shown in adults receiving rFVIIa for off-label indications. ${ }^{36,53}$ Since the risk of thrombotic events in children is much lower than adults, and the etiology is likely different, it would be inappropriate to extrapolate the thrombotic risk associated with rFVIIa in adults to children. Thrombotic events have been associated with rFVIIa use in children, but since comparative studies are lacking, it is difficult to know what the risk is. Many of the children receiving off-label use of rFVIIa also receive FFP. Thrombotic events are also associated with FFP use. ${ }^{54,55}$ This makes the interpretation of the reports of thrombotic events in children following the use of rFVIIa and FFP even more difficult. Because of the lack of data showing a mortality benefit, the potential for thrombotic events, and lack of data showing appropriate dosing of rFVIIa, several publications have called for the restriction of off-label rFVIIa use to investigational studies. ${ }^{36,47,53}$

\section{Costs of treatment}

Any review of rFVIIa would be remiss if the costs of therapy were not discussed. Although the cost of rFVIIa varies from country to country and over time, an estimate of US $\$ 1.50$ per microgram is not unreasonable. At a dose of $90 \mu \mathrm{g} / \mathrm{kg}$, the cost of a single infusion of rFVIIa to a $20 \mathrm{~kg}$ five-yearold is $\$ 2,700$. Since multiple infusions are often required to achieve hemostasis, the costs of rFVIIa can easily exceed tens or hundreds of thousands of dollars, or even millions if using rFVIIa prophylactically to treat a hemophilia patient with an inhibitor. ${ }^{26}$

\section{Summary}

rFVIIa has been used to treat children with abnormal bleeding for approximately 25 years. When used to treat children with hemophilia and inhibitors, rFVIIa has been shown to be very effective at controlling bleeding, with an excellent safety profile. rFVIIa has also been used to treat children with abnormal bleeding for a variety of indications besides hemophilia. High-quality evidence when used off-label in children is lacking. However, most studies have shown a reduction in bleeding and blood product use following the use of rFVIIa in children who do not have hemophilia. No mortality benefit has ever been demonstrated. Thrombotic events have been reported in children following its off-label use. Although there is no evidence proving an increased risk of thrombotic events in children receiving rFVIIa like there is in adults, the potential for thrombotic events should be considered in any risk/benefit analysis prior to infusing rFVIIa. The costs of therapy must also be considered. The dose of $90 \mu \mathrm{g} / \mathrm{kg}$ is commonly used for both on-label and off-label situations. There is concern that this may not be the optimal dose.

Virtually every author who has reviewed rFVIIa use in children has called for RCTs. Since rFVIIa has been used offlabel for 15 years and there have only been three RCTs, none 


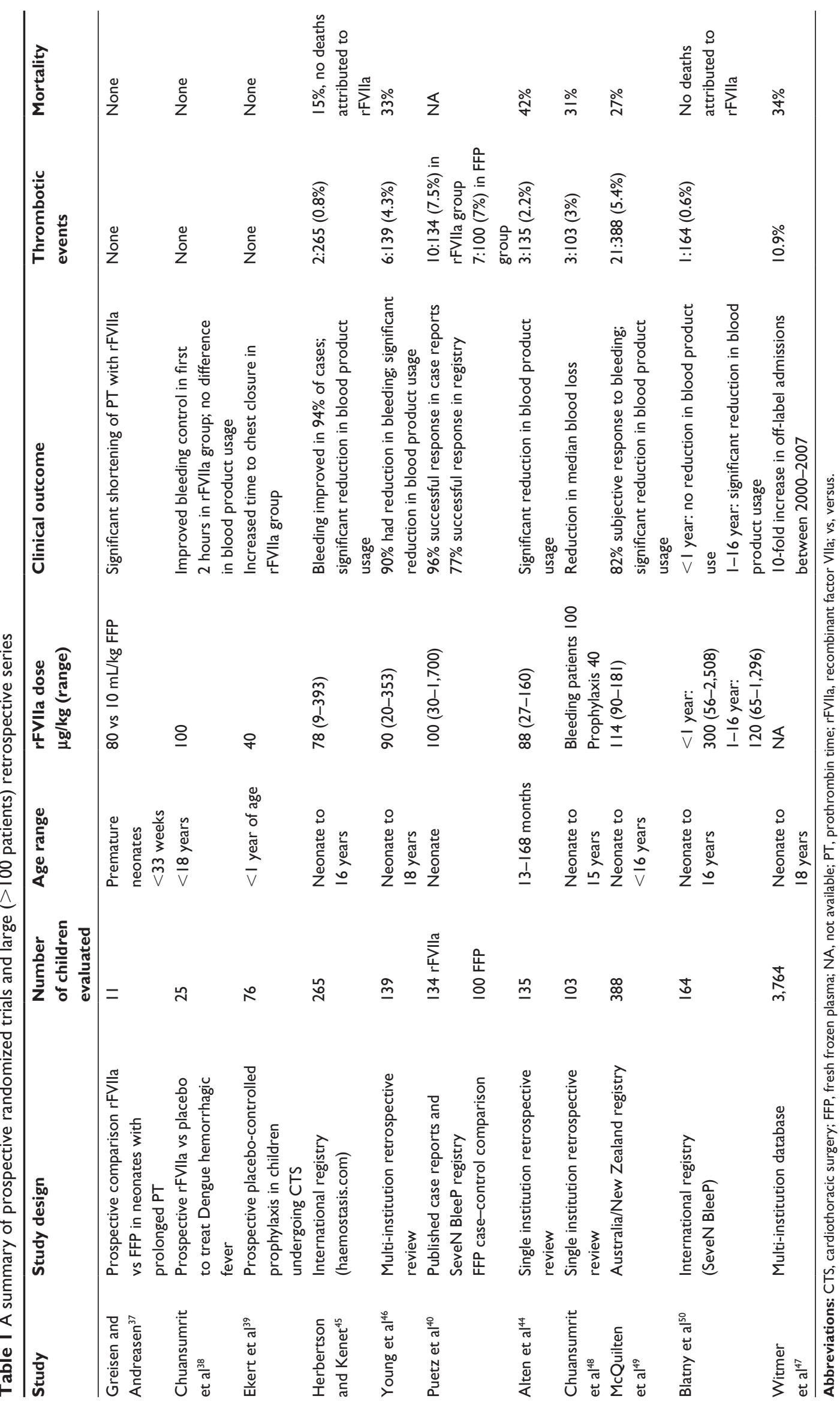


of which were of particularly high quality, we are unlikely to see a high-quality RCT in the near future. Any decisions regarding the use of rFVIIa in children will need to be based on the evidence at hand. In this respect, rFVIIa is similar to many other modalities used to treat children.

\section{Disclosure}

The author reports no conflicts of interest in this work.

\section{References}

1. Rosner F. Hemophilia in the Talmud and rabbinic writings. Ann Intern Med. 1969;70(4):833-837.

2. Patek AJ, Stetson RP. Hemophilia. I. The abnormal coagulation of the blood and its relation to the blood platelets. J Clin Invest. 1936;15(5): 531-542.

3. Craddock CG Jr, Fenninger LD, Simmons B. Hemophilia: problem of surgical intervention for accompanying diseases. Review of literature and report of a case. Ann Surg. 1948;128(5):888-903.

4. Hoyer LW. Hemophilia A. N Engl J Med. 1994;330(1):38-47.

5. Mannucci PM, Tuddenham EG. The hemophilias - from royal genes to gene therapy. $N$ Engl J Med. 2001;344(23):1773-1779.

6. Lofqvist T, Nilsson IM, Berntorp E, Pettersson H. Haemophilia prophylaxis in young patients - a long-term follow-up. J Intern Med. 1997;241(5):395-400.

7. Manco-Johnson MJ, Abshire TC, Shapiro AD, et al. Prophylaxis versus episodic treatment to prevent joint disease in boys with severe hemophilia. N Engl J Med. 2007;357(6):535-544.

8. Macfarlane RG. An enzyme cascade in the blood clotting mechanism, and its function as a biochemical amplifier. Nature. 1964;202:498-499.

9. Davie EW, Ratnoff OD. Waterfall sequence for intrinsic blood clotting. Science. 1964;145(3638):1310-1312.

10. Hoffman M, Dargaud Y. Mechanisms and monitoring of bypassing agent therapy. J Thromb Haemost. 2012;10(8):1478-1485.

11. Puetz J. Optimal use of recombinant factor VIIa in the control of bleeding episodes in hemophilic patients. Drug Des Devel Ther. 2010;4:127-137.

12. Whelihan MF, Zachary V, Orfeo T, Mann KG. Prothrombin activation in blood coagulation: the erythrocyte contribution to thrombin generation. Blood. 2012;120(18):3837-3845.

13. Reactome. A curated pathway database. Available from: http://www. reactome.org/PathwayBrowser/\#DIAGRAM=140877\&PATH=109582. Accessed July 9, 2014.

14. Hedner U, Kisiel W. Use of human factor VIIa in the treatment of two hemophilia A patients with high-titer inhibitors. J Clin Invest.1983;71(6):1836-1841.

15. Kisiel W. Recollections on the discovery of factor VIIa as a novel therapeutic agent for hemophiliacs with inhibitors. JThromb Haemost. 2009;7(7):1053-1056.

16. Hedner U, Glazer S, Pingel K, et al. Successful use of recombinant factor VIIa in patient with severe haemophilia A during synovectomy. Lancet. 1988;2(8621):1193.

17. Hedner U. Recombinant coagulation factor VIIa: from the concept to clinical application in hemophilia treatment in 2000. Semin Thromb Hemost. 2000;26(4):363-366.

18. Lusher JM, Roberts HR, Davignon G, et al. A randomized, double-blind comparison of two dosage levels of recombinant factor VIIa in the treatment of joint, muscle and mucocutaneous haemorrhages in persons with haemophilia A and B, with and without inhibitors. rFVIIa Study Group. Haemophilia. 1998;4(6):790-798.

19. Key NS, Aledort LM, Beardsley D, et al. Home treatment of mild to moderate bleeding episodes using recombinant factor VIIa (Novoseven) in haemophiliacs with inhibitors. Thromb Haemost. 1998;80(6):912-918.
20. Shapiro AD, Gilchrist GS, Hoots WK, Cooper HA, Gastineau DA. Prospective, randomised trial of two doses of rFVIIa (NovoSeven) in haemophilia patients with inhibitors undergoing surgery. Thromb Haemost. 1998;80(5):773-778.

21. Abshire T, Kenet G. Safety update on the use of recombinant factor VIIa and the treatment of congenital and acquired deficiency of factor VIII or IX with inhibitors. Haemophilia. 2008;14(5):898-902.

22. Kjalke M, Ezban M, Monroe DM, Hoffman M, Roberts HR, Hedner U. High-dose factor VIIa increases initial thrombin generation and mediates faster platelet activation in thrombocytopenia-like conditions in a cell-based model system. Br J Haematol. 2001;114(1):114-120.

23. Hoots WK, Ebbesen LS, Konkle BA, et al; Novoseven (F7HAEM-1505) Investigators. Secondary prophylaxis with recombinant activated factor VII improves health-related quality of life of haemophilia patients with inhibitors. Haemophilia. 2008;14(3):466-475.

24. Schulman S, Bech Jensen M, Varon D, et al. Feasibility of using recombinant factor VIIa in continuous infusion. Thromb Haemost. 1996;75(3):432-436.

25. Pruthi RK, Mathew P, Valentino LA, et al. Haemostatic efficacy and safety of bolus and continuous infusion of recombinant factor VIIa are comparable in haemophilia patients with inhibitors undergoing major surgery. Results from an open-label, randomized, multicenter trial. Thromb Haemost. 2007;98(4):726-732.

26. Young G, McDaniel M, Nugent DJ. Prophylactic recombinant factor VIIa in haemophilia patients with inhibitors. Haemophilia. 2005;11(3):203-207.

27. Abbonizio F, Giampaolo A, Coppola A; Italian Association of Haemophilia Centres, Arcieri R, Hassan HJ. Therapeutic management and costs of severe haemophilia A patients with inhibitors in Italy. Haemophilia. 2014;20(4):e243-e250.

28. Bysted BV, Scharling B, Moller T, Hansen BL. A randomized, doubleblind trial demonstrating bioequivalence of the current recombinant activated factor VII formulation and a new robust 25 degrees $\mathrm{C}$ stable formulation. Haemophilia. 2007;13(5):527-532.

29. Poon MC. Clinical use of recombinant human activated factor VII (rFVIIa) in the prevention and treatment of bleeding episodes in patients with Glanzmann's thrombasthenia. Vasc Health Risk Manag. 2007;3(5):655-664.

30. Kenet G, Walden R, EldadA, Martinowitz U. Treatment of traumatic bleeding with recombinant factor VIIa. Lancet. 1999;354(9193):1879.

31. Puetz J, Darling G, McCormick KA, Wofford JD. Fresh frozen plasma and recombinant factor VIIa use in neonates. J Pediatr Hematol Oncol. 2009;31(12):901-906.

32. Vincent JL, Rossaint R, Riou B, Ozier Y, Zideman D, Spahn DR. Recommendations on the use of recombinant activated factor VII as an adjunctive treatment for massive bleeding - a European perspective. Crit Care. 2006;10(4):R120.

33. Bomken C, Mathai S, Biss T, Loughney A, Hanley J. Recombinant activated factor VII (rFVIIa) in the management of major obstetric haemorrhage: a case series and a proposed guideline for use. Obstet Gynecol Inter. 2009;2009:364843.

34. Mathew P. The use of rFVIIa in non-haemophilia bleeding conditions in paediatrics. A systematic review. Thromb Haemost. 2004;92(4): 738-746.

35. Hong I, Stachnik J. Unlabeled uses of factor VIIa (recombinant) in pediatric patients. Am J Health Syst Pharm. 2010;67(22):1909-1919.

36. Simpson E, Lin Y, Stanworth S, Birchall J, Doree C, Hyde C. Recombinant factor VIIa for the prevention and treatment of bleeding in patients without haemophilia. Cochrane Database Syst Rev. 2012;3:CD005011.

37. Greisen G, Andreasen RB. Recombinant factor VIIa in preterm neonates with prolonged prothrombin time. Blood Coagul Fibrinolysis. 2003;14(1):117-120.

38. Chuansumrit A, Wangruangsatid S, LektrakulY, et al; Dengue Study Group. Control of bleeding in children with Dengue hemorrhagic fever using recombinant activated factor VII: a randomized, double-blind, placebocontrolled study. Blood Coagul Fibrinolysis. 2005;16(8):549-555. 
39. Ekert H, Brizard C, Eyers R, Cochrane A, Henning R. Elective administration in infants of low-dose recombinant activated factor VII (rFVIIa) in cardiopulmonary bypass surgery for congenital heart disease does not shorten time to chest closure or reduce blood loss and need for transfusions: a randomized, double-blind, parallel group, placebo-controlled study of rFVIIa and standard haemostatic replacement therapy versus standard haemostatic replacement therapy. Blood Coagul Fibrinolysis. 2006;17(5):389-395.

40. Puetz J, Darling G, Brabec P, Blatny J, Mathew P. Thrombotic events in neonates receiving recombinant factor VIIa or fresh frozen plasma. Pediatr Blood Cancer. 2009;53(6):1074-1078.

41. Tobias JD, Simsic JM, Weinstein S, Schechter W, Kartha V, Michler R. Recombinant factor VIIa to control excessive bleeding following surgery for congenital heart disease in pediatric patients. J Intensive Care Med. 2004;19(5):270-273.

42. Agarwal HS, Bennett JE, Churchwell KB, et al. Recombinant factor seven therapy for postoperative bleeding in neonatal and pediatric cardiac surgery. Ann Thorac Surg. 2007;84(1):161-168.

43. Karsies TJ, Nicol KK, Galantowicz ME, Stephens JA, Kerlin BA. Thrombotic risk of recombinant factor seven in pediatric cardiac surgery: a single institution experience. Ann Thorac Surgery. 2010;89(2): 570-576.

44. Alten JA, Benner K, Green K, Toole B, Tofil NM, Winkler MK. Pediatric off-label use of recombinant factor VIIa. Pediatrics. 2009;123(3):1066-1072.

45. Herbertson M, Kenet G. Applicability and safety of recombinant activated factor VII to control non-haemophilic haemorrhage: investigational experience in 265 children. Haemophilia. 2008;14(4):753-762.

46. Young G, Wicklund B, Neff P, Johnson C, Nugent DJ. Off-label use of rFVIIa in children with excessive bleeding: a consecutive study of 153 off-label uses in 139 children. Pediatr Blood Cancer. 2009;53(2):179-183.
47. Witmer CM, Huang YS, Lynch K, Raffini LJ, Shah SS. Off-label recombinant factor VIIa use and thrombosis in children: a multi-center cohort study. J Pediatr. 2011;158(5):820-825. e1.

48. Chuansumrit A, Teeraratkul S, Wanichkul S, et al. Recombinant-activated factor VII for control and prevention of hemorrhage in nonhemophilic pediatric patients. Blood Coagul Fibrinolysis. 2010;21(4):354-362.

49. McQuilten ZK, Barnes C, Zatta A, Phillips LE; Haemostasis Registry Steering Committee. Off-label use of recombinant factor VIIa in pediatric patients. Pediatrics. 2012;129(6):e1533-e1540.

50. Blatny J, Mathew P, Monagle P, Ovesna P, Fiamoli V. Safety and efficacy of recombinant activated factor VII in nonhemophilia children with severe or life-threatening bleeding: a report from the SeveNBleeP registry. Blood Coagul Fibrinolysis. 2014;25(4):326-332.

51. Okonta KE, Edwin F, Falase B. Is recombinant activated factor VII effective in the treatment of excessive bleeding after paediatric cardiac surgery? Interact Cardiovasc Thorac Surg. 2012;15(4):690-694.

52. Guzzetta NA, Russell IA, Williams GD. Review of the off-label use of recombinant activated factor VII in pediatric cardiac surgery patients. Anesth Analg. 2012;115(2):364-378.

53. Yank V, Tuohy CV, Logan AC, et al. Systematic review: benefits and harms of in-hospital use of recombinant factor VIIa for off-label indications. Ann intern Med. 2011;154(8):529-540.

54. Puetz J, Witmer C, Huang YS, Raffini L. Widespread use of fresh frozen plasma in US children's hospitals despite limited evidence demonstrating a beneficial effect. J Pediatr. 2012;160(2):210-215. e1.

55. Maruyama H, Kitajima H, Yonemoto N, Fujimura M. Frequent use of fresh frozen plasma is a risk factor for venous thrombosis in extremely low birth weight infants: a matched case-control study. Acta Medica Okayama. 2012;66(1):61-66.
Pediatric Health, Medicine and Therapeutics

\section{Publish your work in this journal}

Pediatric Health, Medicine and Therapeutics is an international, peerreviewed, open access journal publishing original research, reports, editorials, reviews and commentaries. All aspects of health maintenance, preventative measures and disease treatment interventions are addressed within the journal. Practitioners from all disciplines are invited to submit

\section{Dovepress}

their work as well as healthcare researchers and patient support groups The manuscript management system is completely online and includes a very quick and fair peer-review system. Visit http://www.dovepress.com/ testimonials.php to read real quotes from published authors. 